UDK: 821.134.2(729.1).09-32 Дијас X. DOI: https://doi.org/10.18485/legado_hispanico.2020.ch15

\author{
Sanja Mihajlovik-Kostadinovska ${ }^{1}$ \\ Universidad de Santos Cirilo y Metodio, Skopje \\ Macedonia del Norte
}

\title{
PARALELISMOS Y DIVERGENCIAS EN DOS CUENTOS DE JESÚS DÍAZ: «EL ENCUENTRO» Y «EL PIANISTA ÁRABE»
}

\begin{abstract}
Resumen
En este artículo nos proponemos analizar dos cuentos del autor cubano Jesús Díaz, publicados con una distancia temporal de treinta y cinco años, uno durante su etapa revolucionaria, otro durante su exilio en Europa. Los dos cuentos hablan de un encuentro entre unos personajes cubanos, pero mientras en el primero ese encuentro se transforma en desencuentro y se niega la posibilidad de diálogo entre los que viven dentro y fuera de la isla, el segundo anuncia cierta reconciliación. A ambos cuentos les une una ambigüedad a nivel textual que potencia las que también emanan a nivel semántico, pero los dos textos presentan también significativas diferencias en el tratamiento de las nociones de ideas y conceptos como la identidad, el otro, el exilio y el exiliado.
\end{abstract}

Palabras clave: Jesús Díaz, exilio, Cuba, cuentos.

$\overline{{ }^{1} \text { sanja.flf@gmail.com }}$ 


\section{Introducción}

«[E]ste Jesús Díaz no existe, este es el seudónimo de un escritor hecho y contrarrevolucionario, que nos quiere hacer daño y mejor es desconocer este cuento» (Cordero 2015: 35). Son palabras de los miembros del jurado que evaluaron los cuentos presentados al concurso organizado por la Unión Nacional de Escritores de Cuba en el ya lejano año 1965. Eran los primeros tanteos literarios del joven Jesús Díaz que, a pesar de no obtener ningún premio, recibió en privado los elogios del jurado que supo reconocer en él un narrador prometedor. Lo curioso de esta anécdota es que casi treinta años más tarde Jesús Díaz se convertiría de verdad en un hombre inexistente para el régimen castrista, tras ser expulsado del Partido Comunista a raíz de la lectura en Zúrich de un polémico ensayo titulado «Los anillos de la serpiente». La libertad de oponerse a la política oficial del régimen y criticarlo abiertamente le costaría el marchar al exilio, primero a Berlín y luego a Madrid donde muere inesperadamente en 2002, a la edad de 61 años.

La trayectoria literaria de Jesús Díaz puede dividirse en dos etapas: la etapa cubana que va desde la publicación de su primer libro de cuentos Los años duros (1966) hasta el exilio en 1991, y una segunda etapa «anticubana», en palabras de Rafael Rojas (apud Cordero 2015: 15), que va desde el exilio hasta su muerte. A la primera etapa de intelectual comprometido con la Revolución corresponden dos libros de cuentos, el ya mencionado Los años duros (1966) y Canto de amor y de guerra (1979), una obra de teatro Unos hombres y otros (estrenada en 1966) y una novela, Las iniciales de la tierra (1987). En este periodo compagina su oficio de escritor con el de profesor de filosofía marxista, cineasta en el Instituto Cubano de Arte e Industria Cinematográfico y director y colaborador del suplemento El Caimán Barbudo, el diario Juventud Rebelde, y luego de la revista Pensamiento Crítico, importantes vehículos de la izquierda cubana, no siempre conforme con la doctrina oficial del régimen. Su segunda novela Las palabras perdidas (1992), según la fecha y las circunstancias de publicación se puede considerar la primera novela del exilio, aunque en realidad la obra fue escrita antes de que partiese para Europa con el manuscrito en la maleta. La siguen otras cuatro novelas, La piel y la máscara (1996), Dime algo de Cuba (1998), Siberiana (2000) y Las cuatro fugas de Manuel (2002). En este periodo es importante destacar también su labor de fundador y director de la revista Encuentro de la Cultura Cubana, que pretendió ser un espacio de diálogo entre los intelectuales que vivían tanto dentro como fuera de la isla, con la oposición al régimen 
como tema pivotante y el exilio como «fuerza conductora» (Oliveira Prates 2014: 89) de todos los números durante la larga vida de esta revista ${ }^{2}$.

La intención de este trabajo es centrarse en dos cuentos de Jesús Díaz que pertenecen a dos épocas diferentes y que representan los dos puntos extremos de las respectivas épocas. El primero, titulado «El encuentro» fue incluido en su primer libro de cuentos Los años duros, y el otro fue publicado en el vigésimo número de la revista Encuentro de la Cultura Cubana. Es decir, se trata de cuentos escritos con una distancia temporal de treinta y cinco años y desde una perspectiva completamente opuesta, tanto geográfica como ideológicamente. En estos dos cuentos nos interesa ver cómo cambian ciertos conceptos como la identidad, las imágenes del otro y las autoimágenes, el exilio y el exiliado para lo cual nos serviremos de algunas nociones teóricas de autores poscoloniales y/o posestructuralistas como Edward W. Said, Homi K. Bhabha y Julia Kristeva. En apoyo de ese método hermenéutico, nos serviremos también de un detallado análisis narratológico y estilístico de los cuentos, coincidiendo en este propósito con el procedimiento semiótico-estructural sugerido por Daniel-Henry Pageux (apud Mall 2002: 366-367) que prevé varias fases de análisis del texto (semiótico, semántico-estructural, antropológico), previas al estudio imagológico propiamente dicho. El análisis de los procedimientos textuales nos ayudará a encontrar ciertos paralelismos entre los dos cuentos, pero será la perspectiva imagológica la que iluminará las considerables diferencias entre ellos.

\section{Una lectura narratológica y estilística de los cuentos}

El cuento «El encuentro» encabeza el libro Los años duros y junto con los dos cuentos siguientes, «El cojo» $\mathrm{y}$ «El capitán», forman un tríptico. La acción en los tres cuentos se sitúa en el mismo punto histórico -en la Cuba de los años cincuenta, durante y después de las huelgas estudiantiles contra Batista en el Instituto de la Habana- y narra las historias de los tres protagonistas, Boby, El Chino y El Rolo, amigos unidos por el ideal revolucionario, pero separados por un error no calculado y una tragedia imprevista. Boby, el narrador del primer cuento, relata, tras su vuelta del exilio en los Estados Unidos, su reencuentro con El Chino que años atrás había perdido la pierna durante la colocación de una bomba en el coche del director del Instituto. En el segundo cuento que le da la voz a El Chino se nos aclara que además de la pierna, El Chino también había

\footnotetext{
${ }^{2}$ La revista se publicó desde 1991 hasta 2009, siendo el número 54 el último en salir.
} 
perdido su «virilidad»y, en un acto simbólico de impotencia y frustración, quiere vengarse de su profesor del Instituto porque corrían rumores de una supuesta relación homoerótica entre ellos. En el tercer cuento, a través de la perspectiva de El Rolo, convertido ya en capitán del ejército revolucionario, se reconstruye su vuelta al Instituto y su encarcelamiento, aclarándose también qué sucedió tras el accidente con la bomba. Estas breves sinopsis nos sirven para entender las interrelaciones entre los tres cuentos que nos presentan tres diferentes prototipos de personajes: el exiliado como traidor, la víctima inocente de la Revolución y el héroe revolucionario. De todos modos, nuestra intención en este trabajo, sin perder de vista el contexto más amplio, es centrarnos solo en el primer cuento, siendo el único que trata la figura del exiliado.

«El encuentro» se divide en cuatro secuencias, separadas por espacios en blanco. La primera se sitúa en el tiempo presente cuando Boby, vuelto ya del exilio, con dos «jebas» ${ }^{3}$ al lado va al encuentro de su viejo amigo El Chino. Este, por su parte, no quiere volver a establecer el contacto con Boby y el (re)encuentro en la calle se reduce a las dos palabras que se intercambian: Boby llamándole por su nombre y El Chino contestándole «pendejo ${ }^{4}$ antes de perderse de vista. La segunda secuencia tiene más o menos la misma longitud que la primera y presenta mediante la analepsis (cuyo uso es frecuente a lo largo de los tres cuentos) y una evidente elipsis, la transformación de El Chino de uno que «no se metía en política» en uno que decide unirse a las huelgas y apoyar la Revolución. La tercera secuencia es la central y la más larga, donde predomina el diálogo entre los tres amigos con ocasionales intervenciones del narrador donde se nota el uso de frases cortas: «Había que decidir. [...] Entonces me sonaste. Estuvo bien. [...] Regresamos» (Díaz 1967: 12) que hacen acelerar el ritmo y recrear el ambiente de tensión de la noche del accidente. En esta secuencia se nos quiere transmitir el sentimiento de camaradería y solidaridad entre los amigos y el altruismo de El Chino que termina como víctima por querer salvar a otro hombre. Con la cuarta secuencia se cierra el cuento de manera circular, volviéndose a situar la acción en el tiempo posterior a la vuelta del exilio de Boby, al que «[le] mandó su familia» (Díaz 1967: 14) para alejarlo de los tumultos, y se vuelve a destacar el irremediable desencuentro entre Boby y el Chino, es decir, entre uno que ha cruzado la frontera y el otro que ha sacrificado lo más «valioso» por la Revolución.

\footnotetext{
${ }^{3}$ En la lengua coloquial de Cuba esta palabra quiere decir «chicas», pero en el texto, según una aclaración a pie de página (Díaz 1967: 12), se refiere a prostitutas.

${ }^{4}$ En América Latina esta palabra se usa también con el significado de «cobarde», según también aclara el propio autor en una nota a pie de página (Díaz 1967: 11).
} 
Los tres cuentos que forman el tríptico comparten el uso del mismo narrador, un narrador en primera persona mediante el cual no solo se muestran las tres diferentes perspectivas de los protagonistas, sino se favorece el ocasional uso del monólogo interior que sirve para exponer las dudas morales que sienten los personajes. Lo curioso del primer cuento «El encuentro» es que este narrador se puede identificar con un narrador en segunda persona, aunque se trata de partes del texto muy breves. Este tipo de narrador se percibe de forma más clara al principio del cuento:

- Chino - te grito. - ¡Chino!

¿No me oyes? ¿No quieres oírme? Eso ya no te lo grito, sólo te lo pienso. No te lo grito porque sé - desde hace un rato - que no quieres oírme. Lo sé desde que me gritaste:

- ¡Pendejo! (Díaz 1967:11)

A diferencia de los otros dos cuentos donde el narrador durante su monólogo interior puede recurrir al uso del tú en una especie de diálogo imaginado con otro personaje, en «El encuentro», el uso del tú tiene una clara función de potenciar la fallida e imposible comunicación entre Boby y El Chino.

Desde el punto de vista estilístico, nos gustaría destacar algunas particularidades del cuento que creemos pertinentes para su análisis. El texto abunda en el uso de diferentes figuras retóricas. El uso de la políptoton en los siguientes ejemplos nos presenta un personaje escindido entre el pasado y el presente: «Así debió haber dicho la mujer que tenía - que tengo - a mi lado. [...] Sólo pude oír -sólo puedo- oír tu voz.» (Díaz 1967: 11). En la siguiente frase se advierte una paradoja «Eran malos tiempos, y él no era cojo.» (Díaz 1967: 11). Se pueden individuar también paralelismos, fortalecidos con anáfora y polisíndeton: «Sentí cómo me halaste, fuerte, y cómo mis pies se pegaron al asfalto del parque, más fuerte, y cómo corriste; lo sentí, te dio, cómo corriste hacia el niple y cómo lo tomaste, y cómo explotó en el aire, demasiado cerca de la pierna.» (Díaz 1967:13). Son frecuentes asimismo ciertas recurrencias, como por ejemplo la repetición hasta cinco veces de la palabra «pendejo» o el calco idéntico de la frase «con tu muleta que manejas tan bien como una pierna» hacia el principio y el final del texto, que se podría interpretar como una especie de resignación del personaje El Chino ante su desgracia. También es interesante destacar que las referencias al contexto geográfico, es decir Cuba, no son directas, sino se hacen mediante la mención metonímica de diferentes lugares o personajes: las ciudades Colón y Pajarito o el dictador Batista. 
En lo que respecta al otro cuento, «El pianistaárabe», temáticamente es muy distante del ambiente revolucionario del primer libro de cuentos de Jesús Díaz, aunque, curiosamente, también habla de un encuentro. Además, el cuento es publicado en la ya citada revista Encuentro de la Cultura Cubana, cuyo título por una parte representa una llamada a reconciliación entre las dos Cubas a ambos lados de la frontera, pero por otra implica la distancia, la división, el diálogo con el otro que, al igual que en el primer cuento, no es un otro lingüística o culturalmente distinto, sino una variante de la mismidad, ideológicamente diferenciada.

La ya aludida distancia temporal de treinta y cinco años entre la publicación del primer cuento «El encuentro» y el otro, «El pianista árabe», hace más que esperada la discrepancia estética entre ellos. Si el primero formaba parte de un libro de cuentos de tendencia realista, con una representación maniqueísta de los personajes inmersos en un mundo de luchas clandestinas e ideales como el heroísmo, la solidaridad, la fe en un proyecto colectivo, el segundo se podría sin duda clasificar como un cuento posmoderno por la presencia de una ironía corrosiva que no acepta certezas o verdades absolutas, así como por la complejidad de la identidad de los personajes que ahora habitan un mundo multicultural, posterior a la caída del Muro de Berlín, con muchas fronteras inestables y borrosas.

En cuanto a la estructura interna de «El pianista árabe», el propio autor no hace una segmentación visible como en el anterior cuento, pero se puede de nuevo intuir una división en cuatro partes. En la primera parte que podemos titular La indiferencia el narrador nos empieza a contar cómo ha sido llevado por un amigo suyo a un bar de mala muerte para escuchar a un pianista, supuestamente de origen árabe que, según el amigo, era un auténtico genio musical. En esta primera parte el narrador no muestra especial interés por conocer al músico en sí, sino espera pasar una noche placentera escuchando jazz. Nada más salir el pianista al escenario, al narrador le asalta la sensación de haber visto en alguna parte a ese pianista, y a partir de esta segunda parte que podemos denominar La duda, el narrador mediante unas analepsis no tan bruscas como en el cuento anterior, rememora una pequeña porción de tiempo en su Cuba natal donde había conocido a un pianista prometedor, llamado Patrocinio Mendoza. Considera las posibilidades de que ese pianista sea él, mas por la diferencia en la actitud (el árabe es más melancólico y más escéptico), el narrador se inclina a pensar que a pesar de la similitud fisonómica, no se trata del mismo hombre. En esta segunda parte podemos notar que el interés del narrador se desplaza desde la música (lo abstracto) hacia 
el individuo (lo concreto). Lo que aquí individuamos como una tercera parte y que denominamos El reconocimiento empieza cuando el pianista comienza a tocar la famosa pieza musical cubana «El manisero» y por la manera en la que el pianista pronuncia la palabra «maní», al narrador ya no le queda ninguna duda de que se trata de un impostor, es decir, de que el pianista no puede ser un árabe, sino un cubano. La música aquí pierde la universalidad y la abstracción presentes hasta ahora, y se convierte en un producto cultural, al mismo tiempo que el músico se transforma en su vehículo, perdiéndose de esta manera su individualismo a favor de la colectividad que representa. Al final del concierto, el narrador y su amigo se acercan al pianista para que el primero pueda verificar su hipótesis y resulta que el pianista es el mismísimo Patrocinio Mendoza que tras un accidente de tráfico fue obligado a cambiar su identidad para poder cobrar el dinero de la indemnización. Esta cuarta parte la podemos denominar La confirmación que es únicamente posible a través del diálogo y el encuentro directo con el otro. Aquí la música como lengua universal se queda en un fondo lejano, reservado para las élites, y el foco puesto sobre el personaje del pianista nos revela de nuevo al individuo y su lado humano, así como el constructo cultural impuesto sobre él, del que es ya imposible liberarse.

En las siguientes líneas apuntaremos a algunas similitudes formales que presentan los dos textos, así como unas diferencias importantes. Ante todo, queremos llamar la atención sobre el hecho de que en este cuento, igual que en el anterior, la acción se teje alrededor de una tríade de personajes: el pianista árabe, que tiene un nombre falso, Hassan Ibn Hassan; el amigo del narrador, simplemente denominado «el peruano» que lleva trabajando doce años en París como crítico musical y el narrador, que tampoco tiene nombre y del que únicamente sabemos que es cubano y que se encuentra fuera de Cuba, por razones que no se nos revelan. Es curioso que en el primer cuento los protagonistas tenían apodos, Boby, El Chino y El Rolo, cada uno sugiriendo una otredad distinta: el primero -la estadounidense-, el segundo - la oriental-y el tercero, por extensión, la latinoamericana-, ya que con la palabra «rolo» se designa a los nacidos en Bogotá, Colombia. En «El pianista árabe» tenemos también la alusión a una especie de fraternidad lingüística y cultural, a una supranacionalidad latinoamericana mediante la amistad entre el peruano y el narrador cubano, solo que aquí se complica más el personaje del pianista que reúne en sí tanto al oriental, como al mestizo y al supuesto auténtico cubano.

En ambos cuentos el espacio se evoca mediante la metonimia. Como ya apuntamos en el caso del primer cuento, allí las referencias son 
más escasas, y si no fuera, por ejemplo, por la referencia clara al dictador Batista, el lector no podría situar la acción de una manera inconfundible solo por las otras dos referencias. En «El pianista árabe» la acción se sitúa explícitamente en París, cuya sola mención es suficiente para evocar no solo la geografía sino toda una serie de significados múltiples, mas el autor opta por ofrecernos al principio del relato otras referencias a París y a la cultura francesa, que crean un efecto redundante, hasta paródico en su exageración estereotipada:

Tras doce años de descubrimientos y trabajos mi amigo el peruano se había convertido en el mejor crítico de la vanguardia musical en París. Me había prometido una sorpresa para mí última noche en la ciudad y yo, excitadísimo, lo esperé en el Carrefour de L'Odeon, subí a su Peugeot, nos disparamos hacia el Sena, derivamos hasta aparcar muy cerca Notre Dame e imaginé [...] (Díaz 2001: 119, el subrayado es nuestro) ${ }^{5}$

En los dos cuentos se da también la curiosa coincidencia de que es una única palabra, «pendejo» en el primero y «maní» en el segundo, la que marca un antes y un después en la relación entre los personajes. La palabra "pendejo» se menciona varias veces en el cuento «El encuentro», y casi como si estuviese marcando el ritmo del cuento. Su uso en las situaciones comunicativas evoluciona desde un uso inofensivo, entre camaradas, hacia uno con claras intenciones de insulto. La última mención de esta palabra, su culminación, representa al mismo tiempo la separación entre los personajes y la imposibilidad de diálogo. En el caso del otro cuento, mediante esta palabra no se pretende crear un efecto de crescendo como en el cuento anterior, sino que se marca un punto de giro en la acción y se produce una situación más bien contraria. La palabra «maní» es la que hace posible el reconocimiento y el diálogo, ya que es gracias a la manera de la que el pianista pronuncia esta palabra cómo el narrador puede intuir la verdadera identidad del personaje que presume ser un árabe. 0 sea, a diferencia de «El encuentro», donde el diálogo entre los dos nativos separados ideológicamente es inviable, aquí surge en una situación comunicativa imprevista y justamente porque a los dos personajes les une el mismo origen. Aquí la palabra no interesa tanto desde el punto de vista semántico o pragmático, sino prosódico. Es decir, ese detalle sutil de una lengua que normalmente puede delatar a un hablante no nativo, aquí cumple una función opuesta: traiciona la autenticidad.

\footnotetext{
${ }^{5}$ Hemos destacado también la palabra «vanguardia» por la frecuente asociación de París con ella, ya que al principio del siglo XX representó el centro por antonomasia de irradiación de los movimientos vanguardistas al resto de Europa y también hacia América.
} 
Respecto al narrador en «El pianista árabe», creemos que la particular elección del narrador-testigo cumple una función opuesta a la del otro cuento. En «El encuentro» gracias al uso del narrador en primera y en segunda persona se creaba un efecto de desdoblamiento que aludía a la escisión del ser exiliado y a la separación entre el yo (de fuera) y el tú dialogante (de dentro). En «El pianista árabe» podemos decir que el narrador y el personaje del pianista se confunden hasta cierto punto, estableciéndose así una relación de identificación. El narrador al principio parece querer contar una historia personal, pero esta muy pronto queda absorbida por la historia del otro. El narrador ya no es el protagonista que sufre las vicisitudes de su tiempo, sino se transforma en mero observador de las vidas ajenas. Esta confusión-identificación es visible sobre todo a nivel textual en la parte que corresponde al relato del pianista, donde predomina el estilo directo libre y donde entre las palabras del narrador asoman palabras o construcciones «auténticas» del discurso directo del otro personaje: «pero de disco nada, dijo rien de rien» (Díaz 2001: 122), «haberse ido pa'siempre y pa'l carajo» (Díaz 2001: 122), «cosido y recocido como el único pantalón de su abuelo» (Díaz 2001: 122).

\section{Los cuentos desde la mirada poscolonial}

Los dos cuentos escogidos aquí nos interesan principalmente por la figura del exiliado, del desarraigado, sin embargo, como en ambos hay referencias al otro oriental, consideramos oportuno detenernos brevemente en estas representaciones imagológicas.

En el cuento «El encuentro» uno de los personajes tiene el apodo El Chino, sin que se nos explique su posible procedencia. El uso de este apodo y los de los demás personajes (Boby, El Rolo), creemos que solo sirven para destacar el antagonismo entre los tres amigos, y no va más allá de una alusión estereotipada a lo que ellos representan. Una confirmación de esto encontramos en la frase «como que es chino a lo mejor se amarilló» (Díaz 1967: 12), que corresponde a una imagen reducida al rasgo racial del oriental y sin duda negativa por el tono burlón que la acompaña. Cuando hablemos del personaje del exiliado, Boby, notaremos una similar representación no exenta de prejuicios. El único personaje que se salva de la caricaturización es El Rolo, que en el tercer cuento lleva el sobrenombre El Capitán y encarna los valores de la Revolución.

En «El pianista árabe» la alusión al otro está presente ya desde el mero título y su imagen es mucho más compleja. Hasta que se revele la verdadera identidad del pianista, su representación corresponde a lo 
que Edward Said $\left(2003^{6}\right)$ llama una representación orientalista. El árabe desde el principio atrae por su misterio y por su exotismo. Viene de una «tierra remota» (Díaz 2001: 119) y conoce los «secretos de la música árabe» (Díaz 2001: 119). En la actitud del amigo del narrador, el crítico peruano naturalizado francés, notamos una típica postura del occidental que «descubre» al oriental, lo observa desde la distancia para convertirlo en su «objeto de estudio» (Said 2003: 98) y para poder aclarar «el rol especial» de su intromisión (Said 2003: 75) en Europa, y no solo en una parte cualquiera, sino en su mismísimo centro simbólico -París. Es decir, la relación que entre ellos se establece no es una relación entre pares, sino una relación jerarquizada, o, de nuevo en palabras de Said: «The Orient was, therefore, not Europe's interlocutor, but its silent other» (Said 2001: 205). Por esto, hasta que no produzca el reconocimiento por parte del narrador (y con ello, su desmitificación), el árabe solo puede hacer, actuar -en este caso tocar el piano- pero no hablar, lo cual corresponde a la descripción de un foráneo, un extranjero definido por Kristeva (1991: 16) del que hablaremos más adelante.

Las coordenadas espaciales que se vinculan al árabe también corresponden a una visión orientalista. Los dos amigos van a escuchar al pianista en una «gruta» y más adelante en el texto se nos dice que normalmente toca en «tugurios de París, Londres o Ámsterdam» (Díaz 2001: 123). 0 sea, el hecho de que no pertenece a la cultura dominante ni sea visible para un público más amplio puede leerse literalmente como una deliberada búsqueda de anonimato por parte del personaje que teme ser revelado. Sin embargo, metafóricamente alude a la marginalización del otro, el no europeo, al que se le reservan solo los lugares aislados, porque el oriente (el otro) es el «yo subterráneo de Europa» (Said 2003: 15).

Lo particular de este cuento es que, tras la revelación de la verdadera identidad del pianista, posible gracias al diálogo con él o más bien a su monólogo desahogante, se deconstruye la visión orientalista. En la mentalidad occidental, entre los estereotipos que se le atribuyen al oriental es el de estafador (Said 2003: 46), pero en la historia que cuenta Patrocinio Mendoza, se descubre que los roles se han invertido y que todo el engaño ha sido tramado por unos occidentales, es decir, el abogado y el médico del hospital dondePatrocinio estuvo hospitalizado tras elaccidente. $\mathrm{Al}$ ser confundido con un árabe «sans-papier», simplemente por el color de su piel (Patrocinio era mulato y el narrador irónicamente dice que se

\footnotetext{
${ }^{6}$ Para los fines de este trabajo nos hemos servido de la versión en macedonio del famoso libro de Edward Said, Orientalismo. Las citas tomadas de él serán traducción nuestra al español.
} 
parecían «como una gota de agua sucia a una limpia» (Díaz 2001: 120)), se presenta la posibilidad del cambio de identidad. Sin embargo, la ironía de esta transformación consiste en el hecho de que la nueva identidad, y con ella el permiso de residencia en un país extranjero, no se obtiene por iniciativa del propio exiliado, migrante o extranjero, sino gracias a la (presunta) preocupación que el sistema muestra por él. La hipocresía de Occidente no puede ser más manifiesta. Se aprovecha del árabe-cubanosea-quien-sea, le ofrece a cambio todos los lujos de una vida occidental (el BMW que tiene el pianista es solo un símbolo de ella), no obstante, lo mantiene marginalizado, convertido en un ciudadano invisible, en un «objeto pasivo» (Kristeva 1991: 101). De todas formas, el cuento presenta también una posible lectura positiva y esperanzadora. En la confusión del árabe con el cubano vemos una especie de identificación entre dos culturas marginales (desde un punto de vista eurocentrista) respecto a la cultura occidental. La historia del pianista árabe se transforma en la historia de cualquier hombre, de la profesión y de la nacionalidad que sea, que sufre cierto tipo de injusticias. Y aunque no podemos observarlo en un sentido poscolonial estricto, gracias a la mencionada identificación, el hecho de que el pianista habla, cuenta su verdad, se sincera ante dos hombres desconocidos, se puede interpretar como una manera de recuperar la voz silenciada del ser oprimido, la espontaneidad de su oralidad, y con ello, tal vez, la verdadera autenticidad.

La identificación del árabe y el cubano también se puede observar dentro de una tradición de orientalización existente en la literatura cubana. Sus huellas más palpables se encuentran en el modernismo, siendo José Martí y su Ismaelillo la máxima expresión de ello, aunque hay autores que hacen remontar estas referencias al barroco hispanoamericano y a Sor Juana Inés de la Cruz o a la literatura de viajes (Nagy-Zekmi 2008: 14). En el contexto del modernismo, por ejemplo, se puede individuar la exotización del árabe, es decir una visión predominantemente orientalista. La figura del árabe llega a ser actual también durante la Revolución Cubana en la que han tenido gran impacto las guerras de independencia del Magreb, lo cual ha redundado también en la imaginación literaria y cultural. A raíz de estas guerras, sobre todo la guerra de independencia de Argelia, el Oriente para Cuba se transforma en su «great complementary equal» (Rodríguez Drissi 2012: 19), un término antitético al que usa Said para referirse a Occidente y su "great complementary opposite», es decir Oriente. En resumen, la imagen del oriental en la literatura cubana ha sido cambiante, tanto a lo largo de los siglos como en las producciones individuales de un mismo autor, pero aquí nos serviremos de las dos 
principales representaciones, apuntadas por la autora Rodríguez Drissi (2012: 77): la que contiene elementos de «relación hegemónica» (el moro como diferente, como no-blanco) o la que contiene elementos de «identificación afectiva» (el moro como el que ha sufrido destierros, como el subyugado a un dominio colonial, como símbolo de libertad, resistencia, coraje).

Hemos podido constatar esta ambivalencia como rasgo de la visión del otro en el segundo cuento «El pianista árabe», o más bien la evolución desde una relación hegemónica» hacia una relación de «identificación afectiva». En lo que concierne al primero, «El encuentro» allí no podemos estar hablando de un auténtico otro, ya que solo se trata de un apodo orientalizado que toma uno de los personajes, ni de una imagen del árabe o del moro, presentes en la literatura cubana que acabamos de mencionar. Pero la visión simplista o estereotipada, típica de cualquier representación imagológica en este cuento se observa justamente en la autoimage del cubano. Los rasgos negativos como frivolidad, cobardía o egoísmo se le atribuyen al que está o se atreve a cruzar la frontera imaginaria entre «ellos»y «nosotros». Mientras las simpatías se reservan solo para los que se quedan dentro y a los que se pueden atribuir los gloriosos atributos de resistencia, coraje y dignidad. En este cuento no caben las diversidades o posibles «identificaciones afectivas» con ningún otro, sea occidental (estadounidense), o sea oriental (chino).

\section{Los cuentos desde la perspectiva del exiliado}

Cuando al principio de este trabajo dijimos que vamos a considerar el cuento «El encuentro» por separado, es decir, sin tomar en cuenta para un análisis detallado los restantes dos, explicamos que la razón consistía en el hecho de tener este primer cuento al exiliado como personaje principal. Al leer el cuento aisladamente del contexto más amplio -el históricoy del contexto más restringido -el libro de cuentos que lo incluye- se sugiere una lectura, si no opuesta, por lo menos ambigua del texto. Boby, protagonista y narrador de este cuento parece sentir sinceramente la pérdida de su amigo El Chino. Rememora con lamento los años en que los tres amigos iban a casas de prostitutas, se divertían juntos y luego se unieron a la resistencia contra Batista. Su vuelta a Cuba tras «el exilio, al que [le] mandó [su] familia» (Díaz 1967: 14) (nótese la ironía y la paradoja de esta frase) y su reencuentro con los viejos camaradas no difieren mucho de cualquier vuelta y reencuentro tras una separación, por el motivo que sea. Boby los nota diferentes, «con ideas muy raras y muy peligrosas» 
(Díaz 1967: 14); él también está cambiado: «Allá estudié y comprendí que la vida era diferente, que era corta y que había que vivirla.» (Díaz 1967: 14). Esta última frase podría pertenecer perfectamente a un cínico, a uno desencantado de la Revolución (en el que de hecho se convertirá el autor Jesús Díaz) y tener validez en el sentido de que el exilio puede ser una opción justificada y razonable. Sin embargo, esta lectura del texto no solo es engañosa por la simpatía que despierta el personaje de Boby, sino también errónea. Teniendo en cuenta los dos contextos a los que aludimos previamente, se plantea la única lectura posible (por lo menos la que tuvo en mente el autor al dirigirse al lector implícito de su tiempo) que es la de denigrar la figura del exiliado. El exiliado en los años posrevolucionarios se transforma, según apunta Rojas (2002: 169), en un auténtico «arquetipo» que representa «todos los valores negativos, según el código de las buenas costumbres comunistas: egoísmo, frivolidad, altivez, indiferencia, soberbia, abulia, pasividad.» Tal vez no todas estas cualidades se le podrían atribuir al personaje de Boby, porque no es indiferente ni pasivo ni soberbio cuando se trata de su participación en las huelgas o incluso después de su partida al exilio: «supe que habías perdido la pierna, y lloré. Te escribí, pero no me contestaste» (Díaz 1967: 14). De todas formas, dejando de lado la perspectiva del propio narrador y leyendo el cuento desde una postura irónica, se notan indudablemente el egoísmo de Boby que se fue a estudiar a los Estados Unidos, dejando a sus compañeros y su frivolidad al aparecer ante El Chino con dos prostitutas al lado, lo que, según subraya Cordero (2015: 107), representa metafóricamente la encarnación de «principios y valores contrarrevolucionarios». Cordero (2015: 107) también llama la atención sobre la diferencia en los tres títulos de los cuentos que forman el tríptico, que no es fortuita. Los dos restantes cuentos llevan como título el apodo de los protagonistas, mientras el primero lo esconde deliberadamente, justo porque no merece ser nombrado por carecer el personaje de valores revolucionarios.

Irónicamente, el propio autor años después se convierte en un exiliado, con lo cual también en una especie de traidor de estos ideales juveniles, plasmados en su primer libro de cuentos. De todas formas, tanto a través de sus novelas como a través de su revista Encuentro de la Cultura Cubana, no dejará de preocupase por todo lo que atañe a su país natal. El exilio se convertirá para él, como para cualquier exilado, en un tema doloroso que se asomará inevitablemente en su ficción o en sus artículos periodísticos ${ }^{7}$.

\footnotetext{
${ }^{7}$ En otro cuento, titulado «Preguntas al polvo» que es prácticamente el primero de los dos cuentos de Jesús Díaz, publicados en la revista Encuentro, la visión del exilio es muy
} 
El cuento «El pianista árabe» no habla explícitamente de ningún exiliado. Es decir, no se menciona ningún motivo político como posible razón que hubiera empujado a alguno de los personajes, el peruano y los dos cubanos, a vivir o encontrarse en Francia. Dado el contexto en el que aparece este cuento, la revista de la diáspora Encuentro, el exilio se puede considerar un tema implícito en el cuento, o mirado de otra manera, el exilio aquí se sale de su limitado marco histórico-geográfico para confundirse con cualquier desplazamiento más o menos forzado, en el que los motivos ya no están en primer plano, sino sus consecuencias. Tal vez, por lo menos en lo que concierne al personaje del pianista, sería más apropiado hablar de un migrante económico, ya que él mismo nos informa que había venido a París para «tocar una semanita en una boîte de mala muerte para buscarse unos francos y ver si podía grabar un disquito» (Díaz 2001: 121-122). Sin embargo, el uso de los diminutivos, la falta de una intención expresa de querer quedarse en París y el posterior accidente por el que se ve obligado a no volver a su país, en nuestra opinión, son trucos de los que se sirve el autor para que el motivo económico tampoco resulte inequívoco, tal vez con el propósito de encubrir otros motivos - los políticos- o con el propósito apuntado arriba -de acercar temáticamente el cuento a lo se podría denominar como «literatura sin residencia fija» o «literatura del desplazamiento» (Ingenschay 2010)-. De ahí, el cuento no nos habla ni de un exiliado, ni de un migrante, sino de un extranjero. El extranjero, en palabras de Kristeva (1991: 7) es uno que no pertenece a ningún lugar, ningún tiempo, que ha perdido su origen, que tampoco puede arraigarse en algún lugar, que vive en un presente suspendido. Nada más exacta parece esta definición aplicada al protagonista de nuestro cuento. Es prácticamente invisible para la sociedad francesa, se mueve constantemente entre varios países, nadie sabe que en realidad es cubano y su vida se podría resumir en sus actuaciones, o sea, dura mientras dura la música, ese "presente suspendido». Hay otras sorprendentes coincidencias entre el texto de Kristeva y la representación del sujeto diaspórico del cuento de Jesús Díaz. Dice Kristeva (1991: 8): «His time? The time of a resurrection that remembers death and what happened before, but misses the glory of being beyond: merely the feeling of a reprieve, of having gotten away.» Patrocinio Mendoza recuerda el punto exacto de su muerte simbólica: «había ocurrido exactamente hacía ocho años, tres meses, doce días

desgarradora. El texto es imaginado como un diálogo fallido entre la madre muerta que no quería dejar Cuba, el «maldito país» (Díaz 1999: 119) y el hijo que había ido al exilio y que vuelve tras años de estar separado e incomunicado con ella. 
y quine horas» (Díaz 2001: 121). Poder contarle a alguien lo sucedido y la razón de su nueva identidad es como una manera de «aliviarse» y «resucitar» la vieja identidad, aunque sea solo por un instante. El pasado permanece como su único refugio seguro, lo único firme a lo que atenerse, mientras el futuro es borroso, como la noche oscura en la que desaparece en su flamante BMW. El extranjero, según Kristeva (1991: 12), está libre de las ataduras con su pueblo, pero completamente solo. Igual que el pianista, condenado a vivir en la clandestinidad, usando las múltiples identidades que tiene.

Siguiendo a Mandolessi (2010), podemos concluir que el primer relato, aunque no pertenece a la literatura del exilio propiamente dicha, habla de la figura del exiliado desde una perspectiva dicotómica, donde se contraponen dos espacios distintos, muchas veces irreconciliables. Por otra parte, «El Pianista árabe» guarda similitudes con la literatura migrante, ya que ofrece «un mapa transnacional, cosmopolita, híbrido y multilingüe; que retraza las fronteras construyendo nuevos puentes ente el Tercer y el Primer mundo» (Mandolessi 2010: 74). Aquí, la figura del exiliado, si observamos a los personajes de este cuento como alter-egos del autor, ya no es un exiliado ni de los años juveniles del revolucionario Jesús Díaz, ni de un exiliado escindido entre su país de origen y su nuevo destino, entre el pasado y el presente. Es un ser que habita los espacios «in between», como los llama Bhabha (1990: 4), es decir vive en «unas temporalidades ambivalentes de espacio-nación» (Bhabha 1990: 294).

\section{A modo de conclusión}

Es incuestionable que el curso de una literatura nacional nunca es lineal y que ninguna ha sido exenta de contradicciones internas, lagunas, fenómenos conflictivos o liminares. El caso de la literatura cubana es probablemente unos de los más interesantes en el contexto hispanoamericano por la complejidad de su identidad, escindida entre un pasado colonial y una problemática y tardía descolonización, entre independentismo y anexionismo, entre el orgullo revolucionario y el desencanto posrevolucionario, entre la Cuba blanca, la Cuba negra y la Cuba mestiza. En este trabajo hemos visto cómo perviven, evolucionan y se transforman estas dualidades y ambigüedades en la obra de un mismo autor, el cuentista, novelista y cineasta cubano Jesús Díaz. Hemos confrontado dos cuentos que hablan de un encuentro entre dos cubanos y hemos visto cómo ambos, sirviéndose de imágenes prefiguradas del otro, plantean la posibilidad o la imposibilidad de diálogo entre el pasado y el presente, entre 
el exilio y la patria, entre el cubano de fuera y el cubano de dentro. En los dos cuentos tratados aquí la perspectiva del autor cambia desde una visión maniqueísta de la situación en la Cuba posrevolucionaria hacia una visión propia de un mundo multicultural donde el exilio ya no es un estigma, sino una instancia a partir de la cual (re)pensar la(s) identidad(es).

\section{REFERENCIAS BIBLIOGRÁFICAS}

Bhabha 1990: Homi Bhabha. Nation and narration. New York: Routledge and Keegan Paul.

Cordero 2015: Diómedes Cordero. Marcas del silencio. Poética y representación irónica; totalitarismo y cultura en la narrativa de Jesús Díaz. Barcelona: Universidad Autónoma de Barcelona, TDX (Tesis doctorales en Xarxa). Web. 28/09/2019.

Díaz 1967: Jesús Díaz. Los años duros. Buenos Aires: Editorial Jorge Álvarez.

Díaz 1999: Jesús Díaz. «Preguntas al polvo». Encuentro de la cultura cubana, 14: 119-122. Web. 27/09/2019.

Díaz 2001: Jesús Díaz. «El pianista árabe». Encuentro de la cultura cubana, 20: 119-123. Web. 20/07/2019.

Ingenschay 2010: Dieter Ingenschay. «Exilio, insilio y diáspora. La literatura cubana en la época de las literaturas sin residencia fija». Ángulo recto, 2/1: s/n. Web. 20/09/2019.

Kristeva 1991: Julia Kristeva. Strangers to ourselves. Translated by Leon S. Roudiez. New York: Columbia University Press.

Mall 2002: Nora Mall. «Imágenes del otro. La literatura y los estudios interculturales». Armando Gnisci (ed.). Introducción a la literatura comparada. Barcelona: Editorial Crítica, 347-389.

Mandolessi 2010: Silvana Mandolessi. «Sobre exiliados, migrantes y extranjeros: hacia una definición terminológica». América. Cahier du CRICCAL, 39: 71-78. Web. 27/09/2019.

Nagy-Zekmi 2008: Sylvia Nagy-Zekmi. «Buscando el Este en el Oeste: Prácticas orientalistas en la literatura latinoamericana». Sylvia Nagy-Zekmi (ed.), Moros en la costa: orientalismo en Latinoamérica. Madrid: Iberoamericana, 11-24.

Oliveira Prates 2014: Thiago Henrique Oliveira Prates. «Encuentro de la Cultura Cubana: exílio intelectual, identidade cubana e dissidência política». Temporalidades - Revista Discente do Programa de PósGraduação em Hisória da UFMG, 6/1: 84-99. Web. 25/09/2019. 
Rodríguez Drissi 2012: Susannah Rodríguez Drissi. Between Orientalism and Affective Identification: A Paradigm and Four Case Studies Towards the Inclusion of the Moor in Cuban Literary and Cultural Studies. Los Angeles: University of California, UCLA Electronica Theses and Dissertations. Web. 20/08/2012.

Rojas 2002: Rafael Rojas. «In memoriam; Jesús Díaz: el intelectual redimido». Istor: revista de historia internacional, III/10: 163-177. Web. 31/07/2019.

Said 2001: Edward W. Said, Reflections on Exile: and Other Literary and Cultural Essays. London: Granta books.

Said 2003: Едвард В. Саид. Ориентализам: западни конщепции за Ориентот. Превод од англиски јазик Зоран Анчевски, Скопје: Магор.

\section{PARALLELISMS AND DIVERGENCES IN TWO SHORT STORIES BY JESÚS DÍAZ: «EL ENCUENTRO» AND «EL PIANISTA ÁRABE »}

\section{Summary}

In this article we intend to analyze two short stories by the Cuban author Jesús Díaz, published with a temporal distance of thirty-five years, one during his revolutionary period, another during his exile in Europe. The two stories speak of an encounter between several Cuban characters, but while in the first one the encounter becomes a failed encounter and the possibility of dialogue between those who live on and off the island is denied, the second announces certain reconciliation. Both stories share an ambiguity on a textual level that enhances the ambiguities that emanate on a semantic level, but the two texts also present significant differences in the treatment of notions such as identity, the other, the exile and the expatriated.

Keywords: Jesús Díaz, exile, Cuba, short stories. 